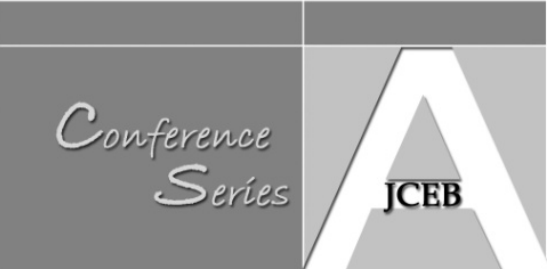

\title{
The Role of Industry Based Learning in a Construction Management Program
}

Mary Hardie and Philip Love (University of Western Sydney, Australia)

\begin{abstract}
Increasingly university administrations are questioning the value of industry experience during a construction management undergraduate program. It is suggested that such work experience is difficult for academics to assess. It may also be unavailable to some students and not closely related to formal learning outcomes. As a result there is pressure to remove the requirement from the graduation eligibility process at many universities. For those who believe that an understanding of the industry context is critical to the development of a construction graduate, there is a need to provide evidence of the breadth and effectiveness of industry experience undertaken by undergraduates. Such evidence may be gleaned from the documents provided by students to support their completion of the required amount of industry experience. Logbooks and employer letters from the last four years at one university were examined and encoded using NVIVO9TM text analysis software. The resulting data indicates that current students are employed throughout the industry in a wide variety of roles and in many types of companies. There is some evidence that the type of experience gained in top tier companies is qualitatively different from that gained elsewhere. There is no indication that student employment is clustered at the low skilled end of the spectrum. Indeed, there is evidence that some students gain positions of considerable responsibility well before they graduate with an undergraduate degree. As such it may well be worth consideration that a specific hierarchy of industry roles be established for students to aim for during their study period. This research suggests that this question merits further discussed between industry advisors and academic providers.
\end{abstract}

Keywords: Work experience; Industry based learning; Construction management education; Assessment

\section{Introduction}

The relationship between work experience undertaken during a university education and graduate employability has long been a significant issue in many disciplines (Murphy and Calway 2008). Whether such experience is made compulsory or not varies a great deal among the different fields of study. In areas as diverse as nursing, teaching, engineering and the social sciences, there is often a specific requirement for practicum or industry placements during the undergraduate period of study (Rhodes and Shiel 2007; Aamodt and Havnes 2008; Tait 2008; Thune 2011). These are often assessed by reflective diaries or similar feedback methods (Brodie and Irving 2007). In the construction management discipline, while there is often a requirement for a certain number of days or hours working in the industry, there has been little research into the roles that students actually play in industry and the extent to which their experience correlates with their academic progress (Senior 1998; Kramer 2008; Koch et al. 2009). It is clear from anecdotal evidence, that both the discipline knowledge and the practical skills developed during university study can be enhanced by actual industry experience before and during the undergraduate program. Access to effective employment placements is, however, problematic for some student categories and in some economic circumstances. It is also difficult for academics to access the value of work experience gained in individual cases (Boud and Falchikov 2006; Costley 2007; Costley and Armsby 2007). For 
these reasons, some sections of academia argue against any compulsory requirement for industry experience before graduation. Nevertheless, the informal knowledge gained through participating in the delivery of actual construction projects, can be of great value in terms of both personal development and professional competencies. For university administrations the critical issue is often how industry experience is funded. Since 2005, the federal government has had very strict requirements for those industry placement courses that may funded in the same way as other university study (Bates 2008). The amount of oversight and direction required is significant. In some construction management programs, the requirement for work experience remains in place, but no funding is received by the university. Consequently, some staff may tend to give only very brief attention to assessing and verifying work experience. As a result, there is an identified gap in the available information on the impact of work experience on construction students. In order to address this issue, this paper reports on the findings of a preliminary analysis of the evidence provided by construction management students of their work experience during study in an undergraduate construction management program.

\section{Value of Industry Based Learning}

Construction management is an applied discipline. While the theoretical aspects of the field are important, they only exist in order to assist in the actual delivery of building projects. For this reason, it is more important in construction than it is in most fields, that educational programs are closely tied to real-life practice (Betts and Liow 1993). Despite this, some researchers have suggested that the adversarial nature of much construction industry interaction means that it is does not generally provide an atmosphere conducive to learning (Bishop et al. 2009). Alternatives to actual work experience may be provided by means of education strategies such as problem-based learning (Schiller et al. 1994); action learning (Lizzio and Wilson 2004) and gaming simulations (Senior 1998). There are, however, cultural aspects of work practice on construction projects which are not readily transmitted in this way because they require first-hand experience. Effective learning in construction management requires careful consideration of the nature of student motivation rather than of purely academic priorities (Pillay and Boulton-Lewis 2000). Skilful communication and building collaborative practice have been reported as essential to a successful integration between workplace and university learning (Cherry 2005). It is not suggested that 'one size fits all', but rather that, in some construction programs, encouragement of a variety of means of concurrent work and study can make a valuable contribution to employability of graduates.

\section{Student Background}

The cohorts that choose to study construction management in different Australian university programs are likely to vary a great deal in background and educational experience. In the university program where this study was undertaken, less than $50 \%$ of students come directly from high school. Approximately one third hold some TAFE or VET qualification on entry. As a result many students already have some level of industry experience before they commence their university study. Mostly, they continue to work in the industry in order to support themselves while studying. Many classes are scheduled at night to enable this to happen. Frequently, students challenge lecturers' opinions if they have work experience in a particular area. This is a healthy process and contributes to the relevance and validity of the educational process. Finding suitable ways to acknowledge the value of on-going work experience while studying is an important educational issue. Work experience is difficult to assess and may be relatively easily manipulated. Challenge tests are sparingly used for those

Hardie, M and Love, P. (2012) 'The role of industry based learning in a construction management program', Australasian Journal of Construction Economics and Building, Conference Series, 12 (1) 12-19 
students who claim their work experience should qualify them for some exemptions. The most direct acknowledgement of the value of work experience is through a compulsory requirement for a set period of industry experience before graduation. Evidence must be provided by means of logbooks and employer reference letters. This evidence was analysed to find a picture of the kinds of work experience that were common and whether there were distinct patterns in the tasks undertaken.

\section{Methodology}

A total of 230 employer letters and student logbooks were assessed using NVIVO9.2 software to encode keywords which described the industry experience of construction management students. This represented $95 \%$ of all the submitted evidentiary documents between 2008 and 2011. The remaining 5\% were submitted in formats that were mainly hand-written are not readily codable with the software. The primary basis for the coding was the categories described in the student logbook provided to the students in the early part of their study program. In addition, some categories were added for activities mentioned in employer letters which were not part of the initial logbook requirements. These items are listed in Table 1. The software enables quick recognition of keywords and synonyms in PDFs and therefore speeds the process of identifying patterns and trends.

Source documents can also be compared by various attributes. In this case, students employed by 'top tier' construction companies were classified as a distinct group and differences in the tasks undertaken by these students were noted. Top tier construction companies were identified using Reed Construction Data lists and other market lists which identify high turnover construction and development companies. Twenty-five companies from the lists were among the employers who provided employment letters or signed off logbooks for the students in this study.

Table 1 Coding items used to classify work experience

\begin{tabular}{|l|}
\hline Nodes \\
\hline 01 Design \\
01.01 Design \\
01.02 Drafting \\
01.03 Documentation \\
01.04 Specification writing \\
01.05 Preparing tender packages \\
01.06 Client liaison \\
\hline 02 Construction \\
02.01 Builder's labourers \\
02.01 Survey and set out \\
02.02 Tradesmen \\
02.03 Foremen or supervisor \\
02.04 Quality control on site \\
02.05 Site administration \\
02.06 Occupational Health and Safety \\
02.07 Manage sub-contractors \\
\hline
\end{tabular}

Hardie, M and Love, P. (2012) 'The role of industry based learning in a construction management program', Australasian Journal of Construction Economics and Building, Conference Series, 12 (1) 12-19 


\begin{tabular}{|l|}
\hline Nodes \\
\hline 03 Commercial management \\
03.01 Contract administration \\
03.02 Business administration \\
03.03 Building and property sales \\
03.04 Marketing \\
03.05 Quality control inspections \\
\hline 04 Estimating \\
04.01 Quantity surveying \\
04.02 Estimating \\
04.03 Tendering \\
04.04 Quotations \\
04.05 Feasibility studies \\
04.06 Pricing variations \\
\hline 05 Project management \\
05.01 Construction planning \\
05.02 Project management \\
05.03 Property development \\
05.04 Progress reporting \\
05.05 Works reporting \\
\hline 06 Building materials \\
06.01 Building product sales \\
06.02 Purchasing \\
06.03 Stores and stock control \\
\hline 07 Miscellaneous \\
07.01 Material testing \\
07.02 Local government \\
07.04 Third party inspections \\
\hline
\end{tabular}

The companies classified as 'top tier' employed 56 students from the 230 total groups surveyed. This represents $24 \%$ of the total work experience gained by the students in this study. It may be that this figure would be significantly higher in older, more established construction programs, but it nevertheless amounts to a significant proportion of the student body. This study will look at whether there is a significant difference in the kinds of experience gained by students in top tier companies compared to other employment in the industry.

\section{Findings of the Study}

The study results are displayed in Figure 1. A broad range of activities were undertaken. The number of employment tasks undertaken by an individual student varied between 12 and 1 with the average being 4.3 tasks. A small number of students were employed by local government or private certifiers. While their experience may have been quite varied, it was only possible to code it under one category. While a few students had experience in peripheral areas such as 'Materials testing' and 'Marketing', this only made up a small part of their total experience. 
The two most common tasks performed by the full cohort of students were 'Estimating' and 'Contract administration'. More than 90 students (39\% of the total) provided evidence of having undertaken these tasks, either as an individual or more commonly in the role of an assistant to a more experienced co-worker. More than 50 students (22\%) undertook the roles of 'Managing sub contractors', 'Site administration' and 'Project management', albeit this may have been in an auxiliary role or on a small project. The least common tasks were 'Materials testing', 'Drafting' and 'Marketing'. As anticipated, there were significant differences between the tasks commonly undertaken by students employed by top tier construction companies and those employed by others. As might be expected, no top tier employees reported working as 'Builders' labourers' while more than 30 students (13\%) employed by other types of company, did have this experience in their repertoire. No top tier employees had experience with 'Feasibility studies', 'Local government', 'Third party inspections', 'Building product sales', 'Specification writing', 'Marketing', 'Drafting' or 'Materials testing'. These tasks are undertaken by specialists in larger companies but not necessarily so in smaller businesses.

Employees of non-top tier companies were significantly more likely to be involved in 'Business administration', 'Progress reporting' and 'Design', although top tier employees also participated in these tasks but at a lesser frequency. While some small and medium sized construction companies were able to provide students with the broadest range of experience, this was not so in every case. A small number of students worked for specialist firms where their experience was limited to specific types of construction processes such as form-working or demolition. Provided that they performed a number of tasks in such firms, this was considered acceptable.

Course material made it clear to students that they should actively seek a variety of experiences in the industry in order to improve their employability and overall understanding of industry context. While it was considered acceptable to start employment in lower level roles such as labouring, in order to achieve a 'Satisfactory' grade for Industry Based Learning the students were expected to demonstrate a progression to higher level tasks during the course of their employment. No more than one third of the 1200 hour total could be counted in labouring or trade capacities which were regarded as 'entry level' work experience. The desired progression path was demonstrated by almost all students who started out in low level jobs. Over the course of the four years that this study covers only a single student failed to demonstrate sufficient industry experience to the extent that graduation was delayed by one semester. The great majority of students demonstrated industry experience far exceeding the 1200 hours required. Most students also provided references from their employers which commended their work ethic and competence. 


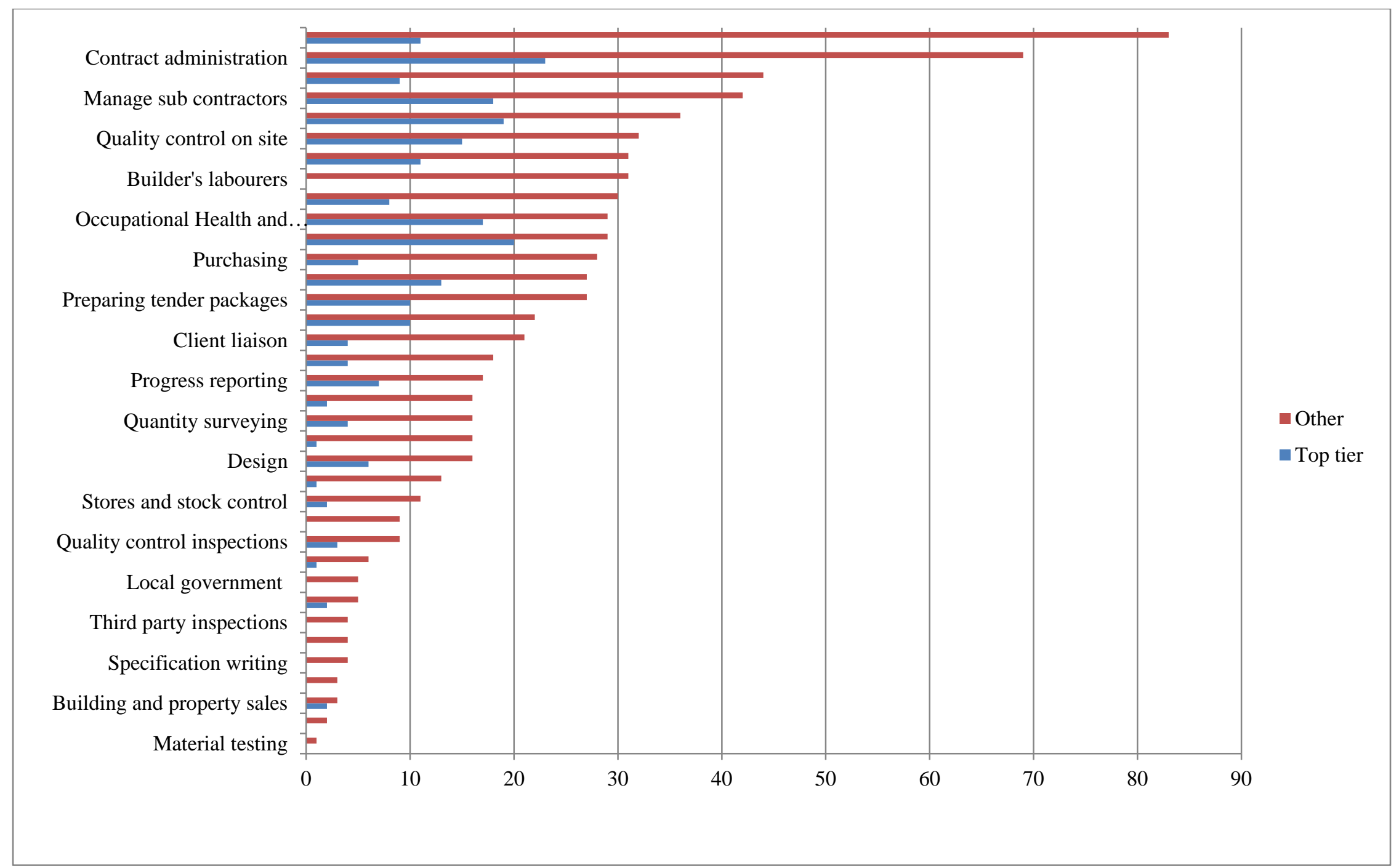

Figure 1 - Most common task categories undertaken by construction students in top tier and other construction companies

Hardie, M and Love, P. (2012) 'The role of industry based learning in a construction management program', Australasian Journal of Construction Economics and Building, Conference Series, 12 (1) $12-19$ 


\section{Conclusion}

Many construction companies take considerable care to ensure that cadets and new employees are exposed to a wide variety of tasks and responsibilities. Several employers stated this explicitly in their letters of evidence. In particular, top tier companies who took on cadets provided evidence of having structured programs which carefully managed the range of experience gained by students. Exposure to several stages of the construction process and to several specialist areas was commonly provided as part of a standard rotation. In small and medium companies, however, student experience tended to be more variable. In some cases it was very diverse, with students carrying out almost all the categories of work experience at one time or another. For others, the nature of the employing firm necessarily limited the kinds of work available. Students in this situation were advised to seek additional experience elsewhere, if possible. It is not possible from the evidence gathered here to state whether large companies provide better career pathways overall than small and medium companies do. This is a matter for further exploration and perhaps for an industry-wide survey.

The benefit to universities of maintaining contact with industry via student employment is threefold. Firstly, there are matters that are more readily understood when presented on a construction site. Visualisations and simulations can only partly replace this actual experience. Secondly, contact with industry employers provides academia with potential avenues to explore in terms of research collaborations and consultation opportunities. Thirdly, students who integrate work and study are able to practice one of the essential skills of the construction manager, that of time allocation and prioritisation. Some may feel that it is not the university's role to monitor student progress in the workforce. For others, valuing and encouraging concurrent work and university learning is a way of improving the overall skill base of the industry while providing opportunity and access to students who otherwise might be excluded from improving their position in the construction workforce. Maintaining a compulsory requirement for industry experience is one way of providing that opportunity.

\section{References}

Aamodt, P.O. and Havnes, A. (2008). 'Factors Affecting Professional Job Mastery: Quality of Study or Work Experience?" Quality in Higher Education, 14, 233-48.

Bates, M. (2008). "Work integrated curricula in university programs." HighermEducation Research \& Development, 27, 305-17.

Betts, M. and Liow, S.R. (1993). 'The relationship between teaching methods and educational objectives in building education.' Construction Management and Economics, 11, 131-41.

Bishop, D., et al. (2009). 'Constructing learning: adversarial and collaborative working in the British construction industry.' Journal of Education and Work, 22, 243-60.

Boud, D. and Falchikov, N. (2006). 'Aligning assessment with long-term learning.' Assessment \& Evaluation in Higher Education, 31, 399-413.

Brodie, P. and Irving, K. (2007). 'Assessment in work-based learning: investigating a pedagogical approach to enhance student learning.' Assessment \& Evaluation in Higher Education, 32, 11-19.

Cherry, N.L. (2005). 'Preparing for practice in the age of complexity.' Higher Education Research and Development, 24, 309-20. 
Costley, C. (2007). 'Work-based learning: assessment and evaluation in higher education.' Assessment \& Evaluation in Higher Education, 32, 1-9.

Costley, C. and Armsby, P. (2007) 'Work-based learning assessed as a field or a mode of study.' Assessment \& Evaluation in Higher Education, 32, 21-33.

Lizzio, A. and Wilson, K. (2004). 'Action Learning in Higher Education: an investigation of its potential to develop professional capability.' Studies in Higher Education, 29, 469-88.

Murphy, G.A. and Calway, B.A. (2008). 'Skilling for the Workforce: A tertiary education response to enrich professional development.' Tertiary Education and Management, 14, 95-109.

Pillay, H. and Boulton-Lewis, G. (2000). 'Variations in Conceptions of Learning in Construction Technology: implications for learning.' Journal of Education and Work, 13, 163-81.

Rhodes, G. and Shiel, G. (2007). 'Meeting the needs of the workplace and the learner through work-based learning.' Journal of Workplace Learning, 19, 173-87.

Schiller, J., Ostwald, M., and Chen, S-E. (1994). 'Implementing a problem-based, distance education undergraduate course in construction management.' Distance Education, 15, 300-17.

Senior, B.A. (1998). 'Infusing Practical Components into Construction Education.' Journal of Construction Education, 3, 92-101.

Thune, T. (2011). 'Success Factors in Higher Education-Industry Collaboration: A case study of collaboration in the engineering field.' Tertiary Education and Management, 17, 31-50. 